\title{
Molecular fingerprinting of Porphyromonas gingivalis by PCR of repetitive extragenic palindromic (REP) sequences and comparison with other fingerprinting methods
}

\author{
R. TEANPAISAN and C.W.I. DOUGLAS* \\ Department of Stomatology, Faculty of Dentistry, Prince of Songkla University, Songkhla, Thailand and \\ * Department of Oral Pathology, School of Clinical Dentistry, University of Sheffield
}

\begin{abstract}
Knowledge of the genetic structure of populations of potentially pathogenic bacteria is important in understanding the epidemiology of diseases. Porphyromonas gingivalis is thought to be an important aetiological agent in periodontal diseases and several methods have been used for typing strains of this species. Here, PCR with primers to repetitive extragenic palindromic sequences (REP-PCR) was compared with three other widely used molecular fingerprinting techniques - restriction endonuclease analysis (REA), ribotyping and PCR with arbitrary primers (AP-PCR) - to type $P$. gingivalis isolates from healthy and diseased periodontal sites. The data obtained with all four methods were in broad agreement and, with one exception, each subject harboured a single unique genotype of $P$. gingivalis. REP-PCR of $P$. gingivalis resulted in the production of 5-10 amplicons, which gave unique electrophoretic patterns in each individual (10 REP-PCR types in 10 patients) and similar results were obtained with AP-PCR. Two isolates from one subject appeared identical by REP-PCR and AP-PCR, but could be differentiated by ribotyping, although there was only minor polymorphism. Thus, ribotyping and REA were the most discriminating methods; however, these are time-consuming and expensive relative to the PCR-based techniques. REP-PCR has the advantage that the same pair of primers is used for all species, whereas AP-PCR needs to be optimised by screening a range of primers. These results show that REP-PCR is a useful and rapid technique for typing $P$. gingivalis.
\end{abstract}

\section{Introduction}

Porphyromonas gingivalis is considered to be a major aetiological agent in rapidly progressive forms of periodontitis. However, its presence is not always associated with disease and strains differ in their virulence $[1,2]$. Therefore, it has been suggested that specific clonal types may be responsible for progressive disease and as a consequence strains that are found at healthy sites may represent relatively avirulent clones [3]. Suitable typing methods are needed to study this. In the past, $P$ gingivalis has been typed by biotyping [4], serotyping [5,6] and antibiotyping [7]. However, these methods designate bacteria to only a few groups, and may not be sensitive enough for differentiating between bacterial isolates of different pathogenicity. Modern typing methods based on molecular biology

Received 9 Sept. 1998; accepted 24 Nov. 1998.

Corresponding author: Dr R. Teanpaisan. techniques have also been applied to $P$. gingivalis. These include restriction endonuclease analysis (REA) of whole chromosomal DNA $[8,9]$, ribotyping $[9,10]$ and amplification of DNA by PCR with arbitrary primers (AP-PCR) $[9,11]$. Recently, a new technique has been introduced known as repetitive extragenic palindromic-PCR (REP-PCR), which is applicable to a wide range of unrelated genera [12]. The technique amplifies DNA sequences between repetitive elements (REP) in the genomes of prokaryotes, particularly gram-negative species, and because the position of these elements varies between strains, polymorphisms may be detected by band pattern. Multiple functions have been proposed for these highly conserved, dispersed REPs including roles in transcription termination, mRNA stability and chromosome domain organisation [13-17]. A few studies have shown that REP-PCR was sensitive enough to distinguish closely related strains of the same species and was a simple and rapid typing method for use in epidemiological 
studies [18-21]. This study compared REP-PCR with the other commonly used molecular methods for fingerprinting $P$. gingivalis isolates.

\section{Materials and methods}

\section{Bacterial isolates}

$P$. gingivalis isolates were obtained from the subgingival plaque of 10 unrelated patients with chronic adult periodontitis as described previously [22]. Briefly, subgingival plaque samples were collected from both diseased (designated as active or inactive according to clinical criteria [22]) and healthy sites in these subjects with two paper points per site, placed immediately into $100 \mu \mathrm{l}$ of pre-reduced Fastidious Anaerobe Broth (Lab M) and transported to the laboratory within $1 \mathrm{~h}$. The samples were then vortex mixed and the whole sample was spread on to Fastidious Anaerobe Agar (FAA; Lab $M)$ and incubated in an anaerobic jar $\left(\mathrm{H}_{2} 10 \%\right.$, $\mathrm{CO}_{2} 10 \%, \mathrm{~N}_{2} 80 \%$ ) at $37^{\circ} \mathrm{C}$ for $7-14$ days. When samples yielded $>10$ black-pigmenting colonies, 10 were picked at random and subcultured for purity. When $<10$ black-pigmenting colonies were found, all were picked. Each isolate was presumptively identified with a short scheme of tests [23] and confirmed by API Rapid 32A. A total of 65 P. gingivalis colonies (isolates) was obtained from the 10 subjects and all were processed for genotyping as described below.

\section{$R E A$ and ribotyping}

Chromosomal DNA was extracted and purified from each isolate by a modification of the method of Owen [24]. REA and ribotyping were performed as described previously [22]. In brief, DNA samples were digested with Pst I, HindIII, BglI and Pst I and HindIII (Sigma) in combination and with the reaction buffers provided by the manufacturer. The cleavage products were run on agarose $0.7 \%$ gels containing ethidium bromide $0.5 \mu \mathrm{g} / \mathrm{ml}$. After electrophoresis, DNA fragments were Southern blotted on to nylon membranes. Ribotyping was performed with a $16 \mathrm{~S}+23 \mathrm{~S}$ rRNA probe (Boehringer Mannheim) from Escherichia coli labelled with peroxidase (ECL kit; Amersham).

\section{$R E P-P C R$ and $A P-P C R$}

A loopful (several colonies) of $P$. gingivalis growth $(24-48 \mathrm{~h})$ was harvested directly from FAA plates into $300 \mu \mathrm{l}$ of distilled water, heated for $10 \mathrm{~min}$ at $100^{\circ} \mathrm{C}$ and centrifuged at $13000 \mathrm{~g}$ for $10 \mathrm{~min}$. Previous tests showed that this procedure generally yielded sufficient template DNA for the PCR reaction. The reaction mixture in a $50-\mu 1$ reaction volume consisted of $5 \mu \mathrm{l}$ of boiled sample as template DNA, $5 \mu 110 \times$ buffer, 1.0 unit Taq DNA polymerase (Promega), $0.2 \mathrm{mM}$ of dNTP, $1.0 \mu \mathrm{M}$ of each primer. Further details of the PCR reaction conditions and the primers used are given in Table 1. The annealing temperatures, times of each part

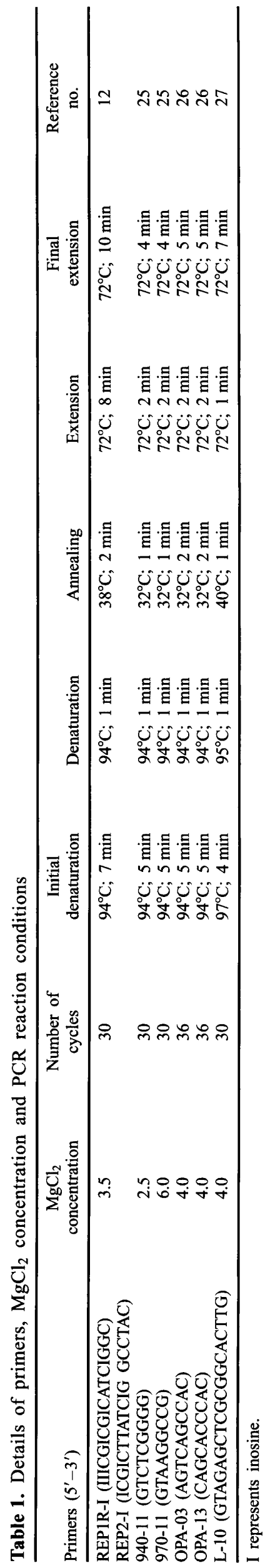


of the cycle and the $\mathrm{MgCl}_{2}$ concentrations used were optimised for each primer pair. All PCRs were performed in an Autogene II thermocycler (Grant) and resultant amplicons were analysed electrophoretically in agarose $1 \%$ gels containing ethidium bromide $0.5 \% \mu \mathrm{g} / \mathrm{ml}$.

\section{Comparison of DNA fingerprints}

Gels of restriction digests (REA), ribotype patterns and PCR amplicon patterns were photographed with Polaroid film and a UV transilluminator (UVP, Cambridge) and then compared by visual inspection. Data collection was based on comparison of the DNA fingerprint of each isolate with that of other isolates from the same patient in adjacent lanes. Representative DNA fingerprints of isolates from each patient were used for comparisons among patients.

\section{Results}

All isolates were analysed by all four molecular methods on more than one occasion. The band pattern produced by each isolate showed the same similarities or differences with other strains on each occasion, although some of the minor amplicons obtained by the PCR methods occasionally varied. This did not influence the ability to differentiate isolates. When common major bands were seen, their size was always consistent by reference to DNA markers run on the same gels.

\section{$R E A$ fingerprinting and ribotyping}

REA fingerprinting of 65 clinical isolates of $P$. gingivalis from 10 unrelated patients showed 11 electrophoretic patterns with each endonuclease used (Pst I, HindIII or BglI alone or Pst $\mathrm{I}+$ HindIII) used

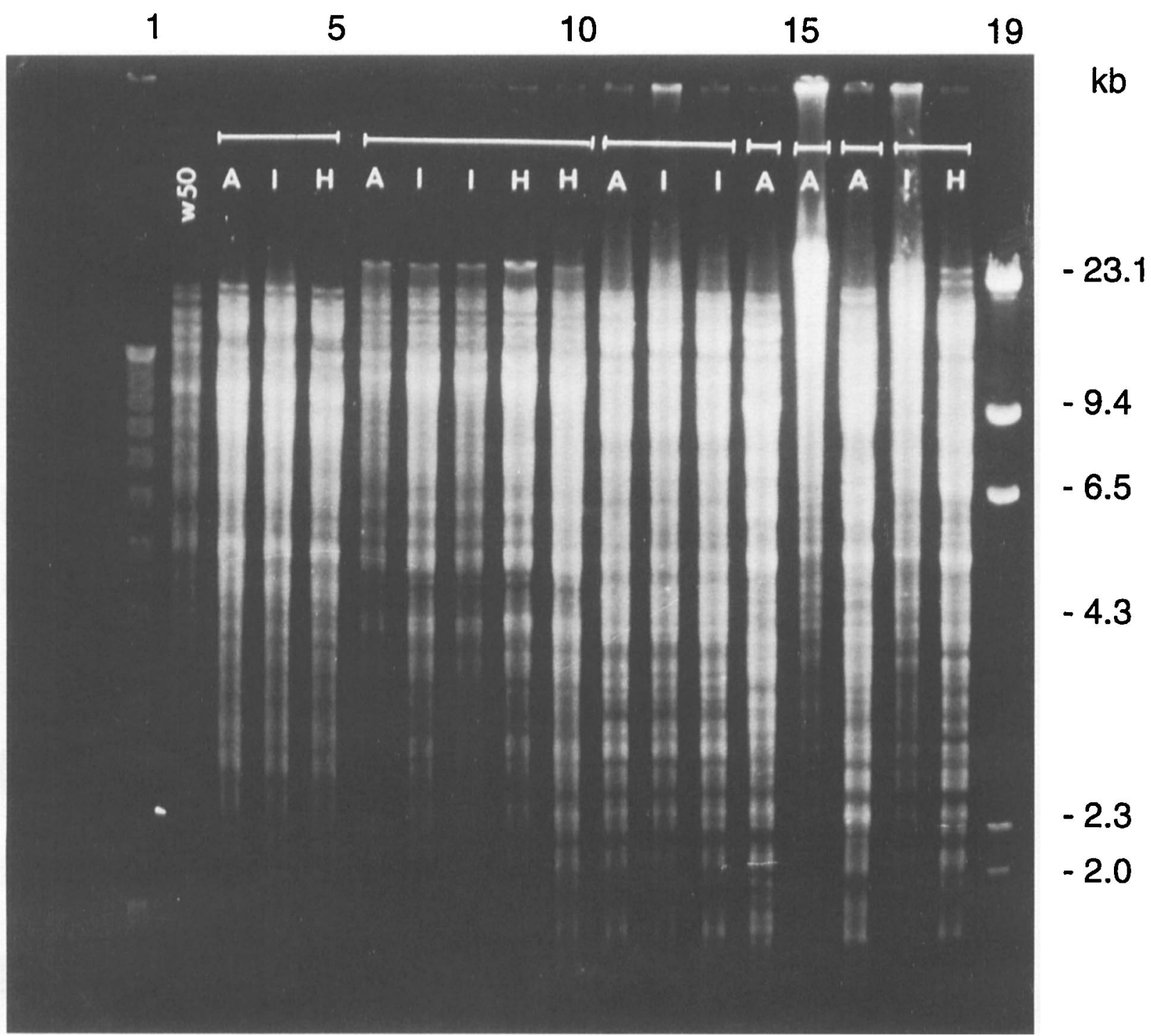

Fig. 1. REA patterns of $P$. gingivalis isolates from seven subjects generated with $P$ st I showing a distinct pattern for each subject. Lanes 1 and 19, 1-kb DNA ladder and $\lambda$ DNA/HindIII DNA size markers respectively; 2, reference strain W 50; 3-5, 6-10, 11-13,14, 15, 16, 17-18, isolates from sites around teeth of seven subjects, respectively. $\mathbf{A}$, actively diseased site; I, inactive site; $\mathbf{H}$, healthy site. 
to digest the DNA. Each of the patterns was unique to a given patient and only one of the 10 subjects yielded $P$. gingivalis isolates with more than one REA pattern. Examples of isolates from seven subjects plus the reference strain W 50 are shown in Fig. 1.

Generally, ribotyping gave similar distinctions between isolates to those obtained by REA, when each endonuclease was used alone. However, the less complex band patterns produced by ribotyping made distinction between different genotypes easier than by REA. Fig. 2 shows the ribotypes of eight isolates from seven subjects generated by digestion of genomic DNA with the restriction endonuclease $P s t \mathrm{I}$; eight distinct patterns can be seen. However, ribotyping was not without its difficulties, as two isolates from two separate subjects showed very similar patterns (Fig. 2a, lanes 2 and 3), but these could be differentiated more easily by digesting with HindIII (Fig. 2b, lanes 2 and 3). Also, lanes 7 and 8 of Fig. 2a and b show two isolates from one subject that had different ribotypes when digested with Pst I (Fig. 2a), but identical patterns when digested with HindIII (Fig. 2b). Consequently, ribotype patterns needed to be checked by digestion with more than one restriction endonuclease before isolates could be deemed identical.

When PstI and HindIII were used in combination to digest genomic DNA, all strains were indistinguishable by ribotyping and showed a single band of $2.2 \mathrm{~kb}$ (Fig. 3).

\section{REP-PCR and AP-PCR}

A random selection of 30 isolates and one reference strain (W 50) was examined by REP-PCR and APPCR. These isolates were chosen to represent strains with different REA types and ribotypes from different subjects and those from different sites within the same individual but with identical ribotypes. Typing by
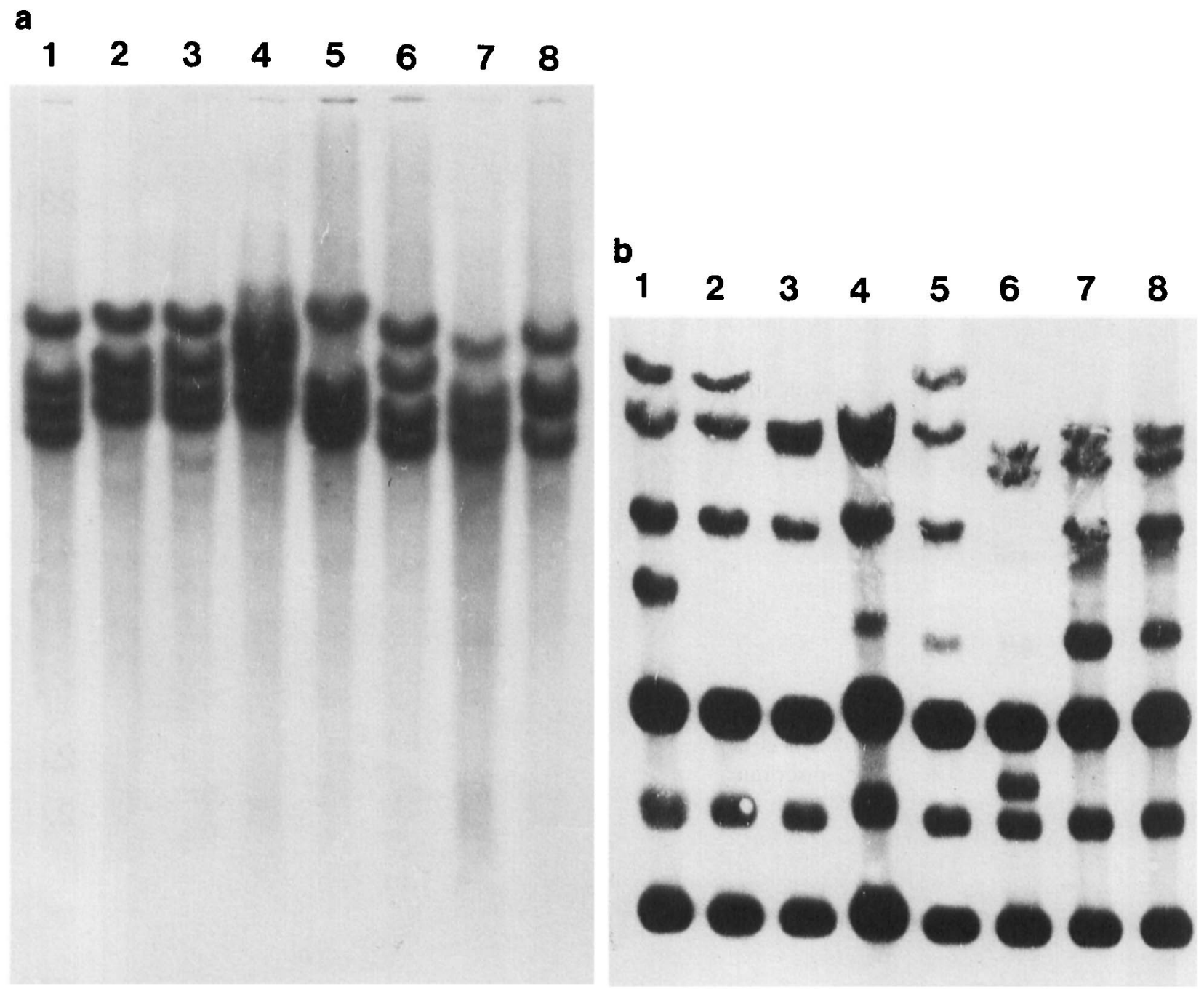

Fig. 2. (a) Ribotypes of eight $P$. gingivalis isolates from seven subjects, generated by digestion with Pst $\mathrm{I}$ : lanes 1-7, isolates from separate subjects; $\mathbf{7}$ and $\mathbf{8}$, isolates from the same subject. All isolates show distinct patterns, although lanes 2 and 3 show very similar banding. (b) Ribotypes of the same eight isolates as in (a) but generated by digestion with HindIII: lanes 2 and 3 are more clearly different than in (a), but lanes 7 and 8 appear identical. 


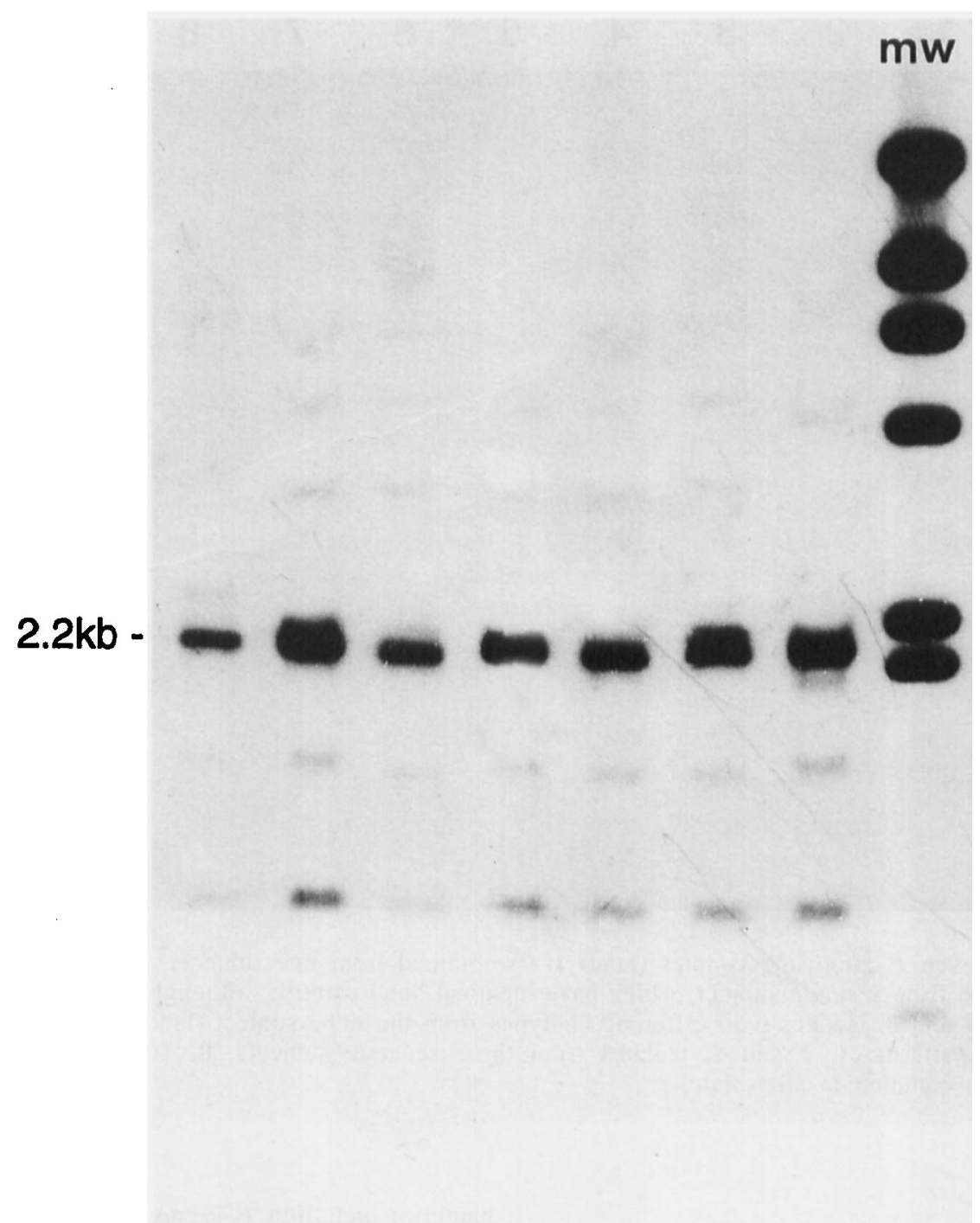

Fig. 3. Ribotype patterns of seven $P$. gingivalis isolates generated by digestion with Pst $\mathrm{I}+$ HindII together. A major common band of $2.2 \mathrm{~kb}$ was seen with all isolates.

REP-PCR clearly distinguished between virtually all strains and confirmed the finding obtained with REA and ribotyping that each unrelated individual harboured a distinct genotype of $P$. gingivalis. Fig. 4 shows seven representative $P$. gingivalis isolates from five subjects; all strains had a major band of $890 \mathrm{bp}$. Two isolates with the same ribotype are shown in lanes 3 and 4 and two isolates with different ribotypes but from the same subject are shown in lanes 7 and 8 . Although REP-PCR was highly discriminating, it did not distinguish between the latter two isolates. All $P$. gingivalis isolates tested so far have given amplicons by REP-PCR.

AP-PCR with a range of primers also gave good discrimination between strains, but with two of the primers (970-11 and 940-11) the study failed to obtain any amplicons with several clinical isolates, despite numerous attempts and varying the PCR conditions (e.g., Fig. 5c, lane 5). The AP-PCR patterns showed the same distinction between isolates as seen with REP-
PCR, but with two exceptions. Two isolates from two unrelated subjects gave identical band patterns with each of two primers (OPA-03 and OPA-13), and very similar patterns with the primers L-10 and 970-11, but with one minor band difference (e.g., lanes 1 and 2 of Fig. 5a, b and c). The strain in lane 2 could not be amplified with primer 940-11 (data not shown). In contrast, these same isolates could be distinguished much more easily by REP-PCR (Fig. 4, lanes 1 and 2). None of the AP-PCR primers nor REP-PCR could distinguish the difference between two isolates with different ribotypes that were obtained from one subject (lanes 6 and 7 of Fig. 5a, b and c, and lanes 7 and 8 of Fig. 4).

AP-PCR of all $P$. gingivalis isolates tested to date showed two common bands at $413 \mathrm{bp}$ and $590 \mathrm{bp}$ with primer OPA-13 (Fig. 5a), a common band of $642 \mathrm{bp}$ with primer L-10 (Fig. 5b) and two common bands at 820 and $1200 \mathrm{bp}$ with primer 970-11 (Fig. 5c). These may be of value for speciation. 


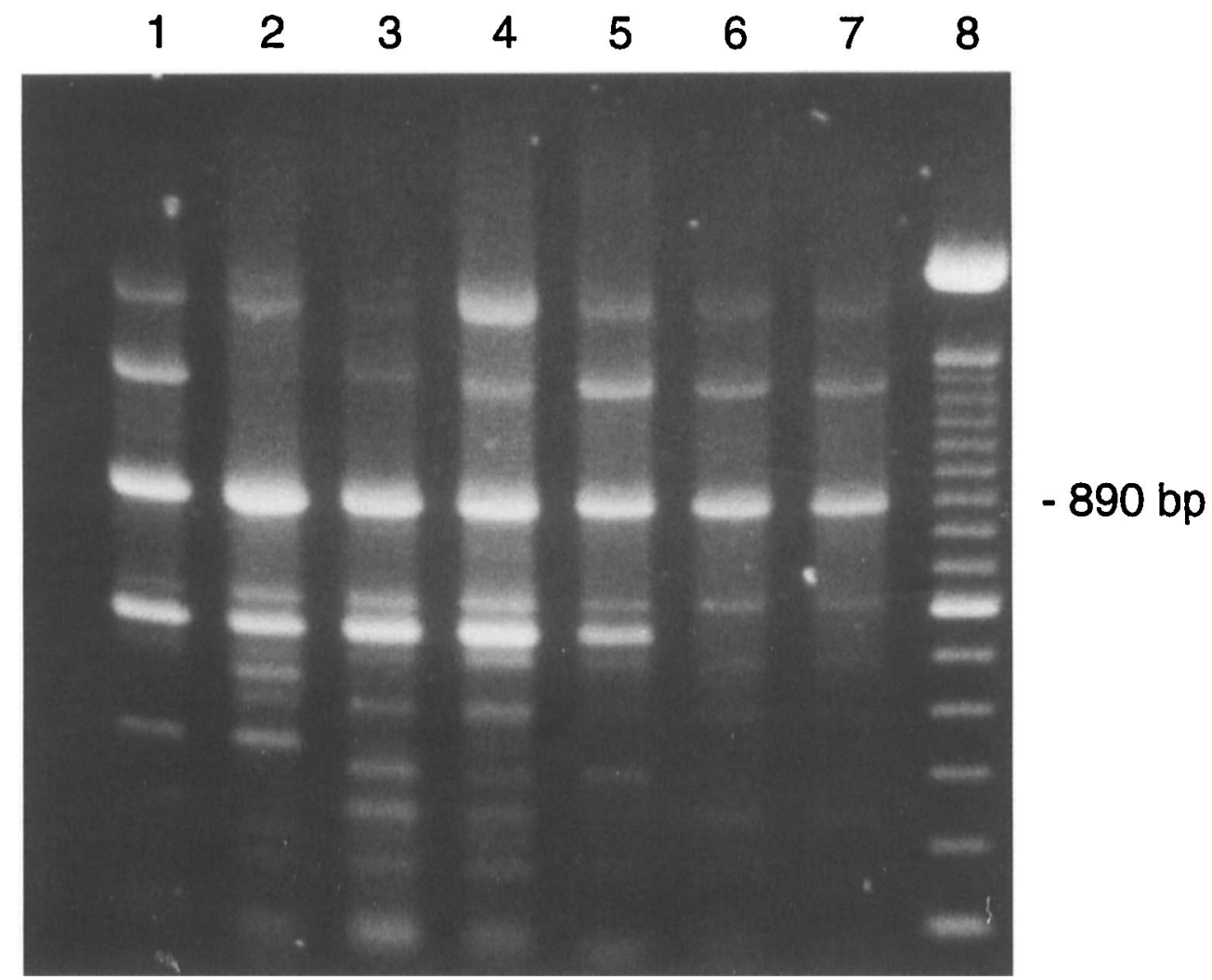

Fig. 4. REP-PCR of seven P. gingivalis isolates (lanes 1-7) obtained from five subjects. Lanes 3 and 4, two isolates with the same ribotype from a single subject, which have identical band patterns, although with different intensities of the uppermost band; 7 and $\mathbf{8}$, isolates with different ribotypes from the same subject (lanes 7 and $\mathbf{8}$ of Fig. 2a) which show identical band patterns; 1, 2 and 5, isolates from three separate subjects; 8, 100-bp DNA ladder. A major amplicon of $890 \mathrm{bp}$ is common to all isolates.

\section{Discussion}

The application of population genetic analysis to oral microbiology could provide important information on the acquisition and transmission of putative pathogens, particularly the exogenous/endogenous origins of those organisms and their geographic variation in relation to disease. For such analysis, sensitive and reproducible techniques for comparing strains are required. The work described here compared a range of commonly used methods with a new less frequently used technique for the typing of $P$. gingivalis isolates.

REA of chromosomal DNA fingerprinting has been shown to be a useful method for many bacterial species, because it offers a precise means of characterising species and of identifying individual strains of closely related bacteria [28]. Also, REA has been used for typing of $P$. gingivalis $[8,9,22]$ and in the present study REA gave useful information on the genotypes and intra- and inter-subject distribution of strains. However, the technique suffers from the production of very complex band patterns and sometimes differences between patterns were so small that comparison and differentiation were very difficult. For this reason, ribotyping was introduced [29] and has been applied successfully to the genotyping of many different bacteria; including $P$. gingivalis $[9,10,22]$. The advantage of ribotyping is that it greatly reduces the number of bands in the fingerprint and so more readily facilitates comparisons between strains. However, the disadvantage of this technique is that it only provides information about specific regions within the genome, and while other regions may vary they would not be detected by the probe used [28]. In addition, ribotyping is a relatively expensive and time-consuming method. In contrast, PCR-based methods offer the convenience of speed, relative cheapness and the requirement for only small amounts of DNA. The use of arbitrary primers removes the requirement for sequence data of a specific gene, and Menard et al. [11,25] have suggested that AP-PCR has advantages over REA and ribotyping for differentiating $P$. gingivalis strains. The present study compared a new PCR-based method (REP-PCR) with REA, ribotyping and AP-PCR to investigate the genotypes of $P$. gingivalis isolates. The data obtained with REA, ribotyping and AP-PCR confirm the findings of van Steenbergen et al. [9], but REP-PCR has not been applied to $P$. gingivalis isolates before. All methods used in the present study were capable of distinguishing the majority of strains and were in broad agreement, but ribotyping was the most discriminating method. For example, some isolates of $P$. gingivalis from a single subject could be 

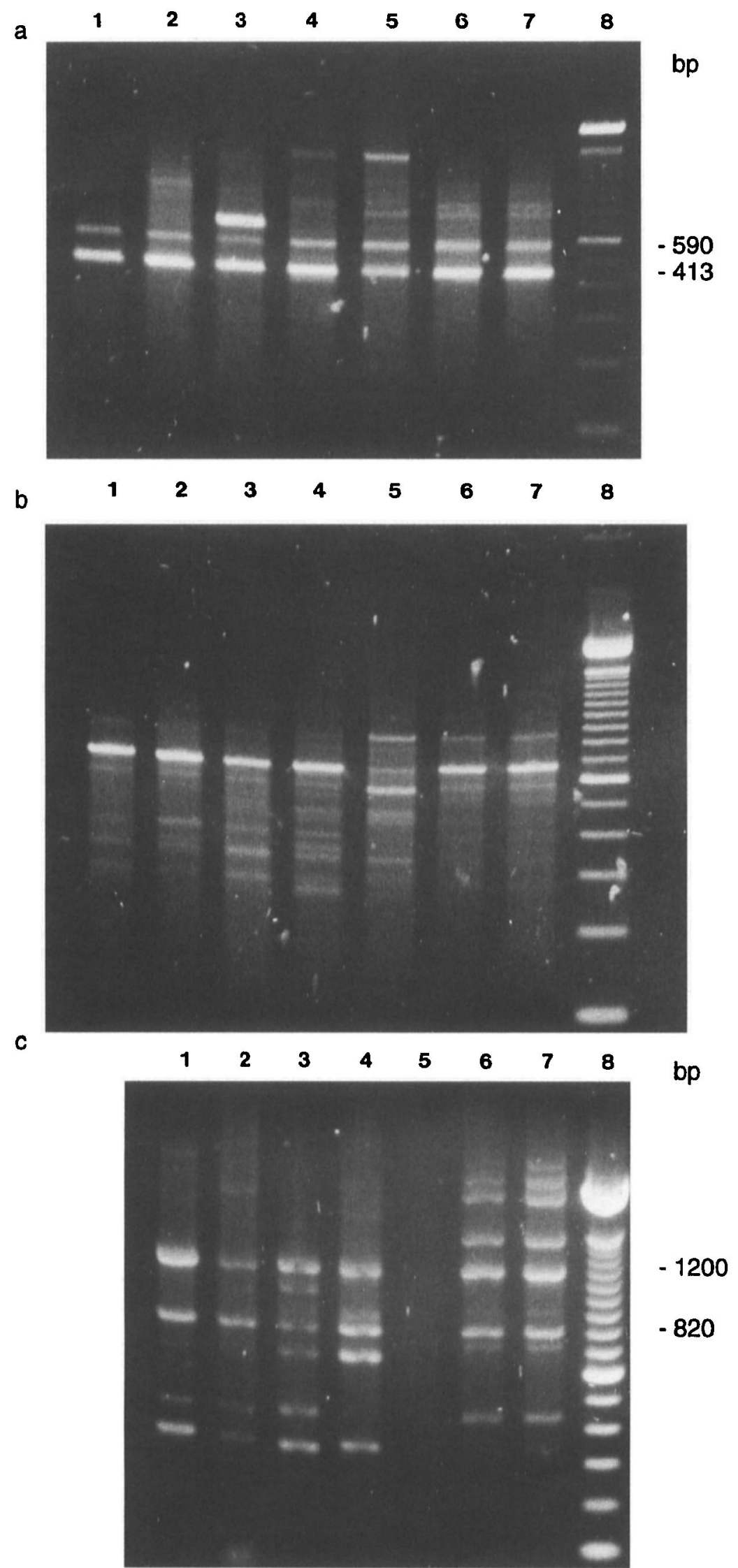

Fig. 5. AP-PCR types of seven isolates amplified with primers (a) OPA-13, (b) L-10 and (c) 970-11. Two isolates, shown in lanes 1 and 2 of (a), (b) and (c), cannot be easily differentiated with any primer but were more clearly distinguished by REP-PCR (lanes 1 and 2 of Fig. 4). Two isolates with different ribotypes from the same patient showed identical patterns with primers OPA-13, L-10 and 970-11 (lanes 6 and 7 of (a), (b) and (c) respectively). Lane 8 in (a), (b) and (c) 100-bp DNA ladder. Some strains did not produce any amplicons with primer 970-11 (lane 5, (c)). Two amplicons common to all isolates could be seen with primer OPA-13 (a), size 413 bp and 590 bp, with 970-11 (c), size $820 \mathrm{bp}$ and $1200 \mathrm{bp}$ and a common band of $642 \mathrm{bp}$ with L-10 (b). 
separated by ribotyping, but these were very difficult to separate by REA and could not be differentiated by REP-PCR or AP-PCR. It appears then that these PCRbased methods cannot distinguish strains that have very small polymorphisms in their genome, but they can easily distinguish less closely related isolates of $P$. gingivalis and have distinct advantages over REA and ribotyping - including production of small numbers of bands (5-10/isolate) - and the results are available within $24 \mathrm{~h}$ of obtaining the pure culture.

AP-PCR requires optimisation, including the screening of a range of random primers to select those suitable for the species under study, while REP-PCR uses a specific primer pair that is applicable to a large number of bacterial species [12], which is a distinct advantage. The AP-PCR primers used in the present study have been described by others as capable of differentiating between black-pigmented species and strains [9, 2527]. However, under the conditions employed here, none of these primers was capable of discriminating between all strains of $P$. gingivalis, indicating that a range of primers should be used to type strains by this method. Mouton et al. [25] described the use of a primer (97011) which distinguished many human and animal strains of $P$. gingivalis, although it failed to distinguish the closely related laboratory strains W 50 and W 83. Also, van Steenbergen et al. [9] found that primer 970-11 could not distinguish between two isolates which had different ribotypes, and this is in agreement with the findings of the present study. Thus, many arbitrary primers suffer from lack of specificity for strain differentiation and isolates yielding identical amplicons should always be checked with other primers before concluding that they are identical strains. Although less of a problem with REP primers, the degeneracy of the primer pairs used also probably accounts for their inability to distinguish $100 \%$ of genotypes.

In conclusion, PCR-based methods offer the advantages of speed and simplicity over REA and ribotyping; however, both REP-PCR and AP-PCR failed to discriminate between closely related isolates. Recently, REP-PCR has also been applied successfully to the differentiation of Streptococcus oralis strains [30]. Consequently, it is suggested that for comparison of strains for epidemiological purposes, REP-PCR should be performed on boiled extracts of whole organisms under the conditions described in Materials and methods. This will provide a fairly rapid screening of strains. If isolates differ in their REP types, they can be taken as being genetically distinct, but if they appear identical they should be subjected to ribotyping for confirmation with more than one restriction endonuclease to digest the genomic DNA.

We are grateful to the Wellcome Trust and to the Thai Academic Affairs for support. We thank Dr Adam Houghton and Mr Jason Heath for their help with PCR techniques and Mr David Thompson for reproduction of the figures.

\section{References}

1. Van Steenbergen TJM, Delemarre FG, Namavar F, de Graaff J. Differences in virulence within the species Bacteroides gingivalis. Antonie van Leeuwenhoek 1987; 53: 233-244.

2. Neiders ME, Chen PB, Suido $\mathrm{H}$ et al. Heterogeneity of virulence among strains of Bacteroides gingivalis. $J$ Periodont Res 1989; 24: 192-198.

3. Socransky SS, Haffajee AD. The bacterial aetiology of destructive periodontal disease: current concepts. $J$ Periodontol 1992; 63 Suppl 4: 322-331.

4. Love DN, Johnson J, Jones RF, Calverley A. Bacteroides salivosus sp.nov., an asaccharolytic, black-pigmented species from cats. Int $J$ Syst Bacteriol 1987; 37: 307-309.

5. Gmur R, Werner-Felmayer G, Guggenheim B. Production and characterization of monoclonal antibodies specific for Bacteroides gingivalis. Oral Microbiol Immunol 1983; 3: 181-186.

6. Nagata A, Man-yoshi T, Sato M, Nakamura R. Serological studies of Porphyromonas (Bacteroides) gingivalis and correlation with enzyme activity. J Periodont Res 1991; 26: 184-190.

7. Notten FJW, Nieman FHM, Mikx FHM. Antibiotypes of Bacteroides gingivalis assessed by antimicrobial disks and multivariate analysis. $J$ Clin Microbiol 1985; 22: 1020-1024.

8. Loos BG, Mayrand D, Genco RJ, Dickinson DP. Genetic heterogeneity of Porphyromonas (Bacteroides) gingivalis by genomic DNA fingerprinting. J Dent Res 1990; 69: 1488-1493.

9. van Steenbergen TJM, Menard C, Tijhof CJ, Mouton C, de Graaff J. Comparison of three molecular typing methods in studies of transmission of Porphyromonas gingivalis. $J$ Med Microbiol 1993; 39: 416-421.

10. Saarela M, Stucki AM, von Troil-Linden B, Alaluusua S, Jousimies-Somer $\mathrm{H}$, Asikainen S. Intra- and inter-individual comparison of Porphyromonas gingivalis genotypes. FEMS Immunol Med Microbiol 1993; 6: 99-102.

11. Ménard C, Brousseau R, Mouton C. Application of polymerase chain reaction with arbitrary primer (AP-PCR) to strain identification of Porphyromonas (Bacteroides) gingivalis. FEMS Microbiol Lett 1992; 95: 163-168.

12. Versalovic J, Koeuth T, Lupski JR. Distribution of repetitive DNA sequences in eubacteria and application to fingerprinting of bacterial genomes. Nucleic Acids Res 1991; 19: 6823-6831.

13. Murry MA, Zhang D, Schneider M, De Bruijn FJ. Use of repetitive sequences and the polymerase chain reaction (REPPCR) to fingerprint the genomes of Frankia isolates. Symbiosis 1995; 19: 223-240.

14. Vila J, Marcos MA, Jimenez de Anta MT. A comparative study of different PCR-based DNA-fingerprinting techniques for typing of the Acinetobacter calcoaceticus-A. baumannii complex. J Med Microbiol 1996; 44: 482-489.

15. Koh-Luar SI, Choo GHB, Tan SLR, Tan CWK. Genomic fingerprints of Samonella species generated with repetitive element sequence-based PCR. World $J$ Microbiol Biotechnol 1998; 14: 17-22.

16. Appuhamy S, Coote JG, Low JC, Parton R. PCR methods for rapid identification and characterization of Actinobacillus seminis strains. J Clin Microbiol 1998; 36: 814-817.

17. Higgins CF, Ames GF-L, Barnes WM, Clement JM, Hofnung M. A novel intracistronic regulatory element of prokaryotic operons. Nature 1982; 298: 760-762.

18. Yang Y, Ames GF-L. DNA gyrase binds to the family of prokaryotic repetitive extragenic palindromic sequences. Proc Natl Acad Sci USA 1988; 85: 8850-8854.

19. Gilson E, Rousset JP, Clement JM, Hofnung M. A subfamily of $E$. coli palindromic units implicated in transcription termination? Ann Inst Pasteur Microbiol 1986; 137B 259-270.

20. Newbury SF, Smith NH, Robinson EC, Hiles ID, Higgins CF Stabilization of translationally active mRNA by prokaryotic REP sequences. Cell 1987; 48: 297-310.

21. Gilson E, Perrin D, Hofnung M. DNA polymerase 1 and a protein complex bind specifically to $E$. coli palindromic unit highly repetitive DNA: implications for bacterial chromosome organization. Nucleic Acids Res 1990; 18: 3941-3952.

22. Teanpaisan R, Douglas CWI, Eley AR, Walsh TF. Clonality of Porphyromonas gingivalis, Prevotella intermedia and Prevotella nigrescens isolated from periodontally diseased and healthy sites. J Periodont Res 1996; 31: 423-432.

23. Laughon BE, Syed SA, Loesche WJ. Rapid identification of Bacteroides gingivalis. J Clin Microbiol 1982; 15: 345-346. 
24. Owen RJ, Borman P. A rapid biochemical method for purifying high molecular weight bacterial chromosomal DNA for restriction enzyme analysis. Nucleic Acids Res 1987; 15: 3631.

25. Mouton C, Menard C. DNA fingerprinting of Porphyromonas gingivalis by arbitrarily primed PCR. In: Genco RJ, Hamada S, Lehner T, McGhee J, Mergenhagen S (eds) Molecular pathogenesis of periodontal disease. Washington, DC, American Society for Microbiology. 1994; 33-46.

26. Matto J, Saarela M, von Troil-Linden B, Alaluusua S, Jousimies Somer H, Asikainen S. Similarity of salivary and subgingival Prevotella intermedia and Prevotella nigrescens isolates by arbitrarily primed polymerase chain reaction. Oral Microbiol Immunol 1996; 11: 395-401.
27. Corney BG, Colley J, Djordjevic SP, Whittington R, Graham GC. Rapid identification of some Leptospira isolates from cattle by random amplified polymorphic DNA fingerprinting. J Clin Microbiol 1993; 31: 2927-2932.

28. Owen RJ. Chromosomal DNA fingerprinting - a new method of species and strain identification applicable to microbial pathogens. J Med Microbiol 1989; 30: 89-99.

29. Stull TL, Lipuma JJ, Edlind TD. A broad-spectrum probe for molecular epidemiology of bacteria: ribosomal RNA. $J$ Infect Dis 1988; 157: 280-286.

30. Beighton D, Alam S. Use of repetitive extragenic palindromic PCR (REP-PCR) to study S. oralis. J Dent Res 1997; 76: 1026 (Abstract). 